\title{
Programas federais em alfabetização: abordagem linguístico-epistemológica
}

Laiana Abdala Martins

Mary Elizabeth Cerutti-Rizzatti

\section{Resumo}

O objeto deste artigo é a formação continuada em alfabetização, delimitandose aos programas Pró-Letramento Linguagem (PL), vigente de 2005 a 2012, e Pacto Nacional pela Alfabetização na Idade Certa (Pnaic), iniciado em 2013, tendo entre os seus objetivos garantir que todos os estudantes estivessem alfabetizados até os 8 anos de idade, ao final do terceiro ano do ensino fundamental. A análise visa relacionar esses programas sob o ponto de vista filosófico-epistemológico em enfoque linguístico. A teoria contempla o Movimento A: enfoque cognitivo-sistêmico e o Movimento B: enfoque na interação social, cada um com duas subdivisões. À luz deles, empreende-se pesquisa documental do Manual do PL e dos Cadernos do Pnaic, que resulta na compreensão de que o PL se caracterizou por uma busca, ainda difusa, de manutenção no Movimento B, enquanto o Pnaic parece sublinhar o Movimento A1: enfoque processual-sistêmico. Os dois programas, porém, convergem no reconhecimento de que ambos os movimentos não podem ser dissociados da formação continuada de alfabetizadores.

Palavras-chave: abordagem epistemológica; abordagem linguística; formação continuada do professor; Programa Pró-Letramento; Pacto Nacional pela Alfabetização na Idade Certa. 


\section{Abstract \\ National literacy programs: a linguistic-epistemological approach}

This article focuses on the continuing education in literacy, restricted to the programs Pro-Literacy Language (PL), in effect from 2005 to 2012, and the National Pact of Literacy at the Right Age (PNAIC) from 2013, which among other things aimed at the acquisition of literacy by all students until their 8 years of age, until the end of the third year of elementary school. The analysis aims to relate these programs from a philosophical-epistemological point of view based on a linguistic approach. The theory contemplates two concepts: Movement A: cognitive-systemic approach and Movement B: focus on social interaction, each with two subdivisions. In the light of these movements, a documentary research of the PL Manual and the Pnaic Notebooks has been conducted, leading to the understanding that the PL was characterized by a search, yet diffuse, for maintaining Movement B, while Pnaic seems to underline Movement A1: a procedural-systemic approach. The two programs, however, converge in the recognition that both movements cannot be dissociated from the continuing training of literacy teachers.

Keywords: continuing teacher training; epistemological approach; linguistic approach; National Pact of Literacy at the Right Age; Pro-Literacy Program.

\section{Resumen \\ Programas federales en alfabetización: abordaje lingüístico- epistemológico}

El objeto de estudio de este artículo es la formación continua en alfabetización, delimitándose a los programas Pró-Letramento Linguagem - PL (Pró-Alfabetismo Lenguaje), vigente desde 2005 hasta 2012, y Pacto Nacional pela Alfabetização na Idade Certa - Pnaic (Pacto Nacional por la Alfabetización en la Edad Correcta) iniciado en 2013, teniendo entre sus objetivos asegurar que todos los estudiantes estuvieran alfabetizados hasta los 8 años de edad, al final del tercer año de la escuela primaria. El objetivo es relacionar esos programas bajo el punto de vista filosóficoepistemológico en enfoque lingüístico. La teoría contempla dos conceptos: Movimiento A: enfoque cognitivo-sistémico y Movimiento B: enfoque en la interacción social. A la luz de esos movimientos, se emprende la investigación documental del Manual del PL y de los Cuadernos del Pnaic, de lo que resulta la comprensión de que el PL se caracterizó por una búsqueda, todavía difusa, de mantenimiento en el Movimiento B, en cuanto el Pnaic parece destacar al Movimiento A1: enfoque procesal-sistémico. Los dos programas, sin embargo, convergen en el reconocimiento de que ambos movimientos no pueden ser disociados de la formación continua de alfabetizadores.

Palabras clave: abordaje epistemológico; abordaje lingüístico; formación continua del profesor; Programa Pró-Alfabetismo; Pacto Nacional pela Alfabetização na Idade Certa. 


\section{Introdução}

Tematizando programas nacionais de formação continuada na alfabetização, nosso objeto é o Pró-Letramento Linguagem (PL) e o Pacto Nacional pela Alfabetização na Idade Certa (Pnaic), os quais, em sequência temporal, envolveram educadores e universidades na última década. O objetivo é compreender as bases linguísticoepistemológicas de documentos pedagógicos desses programas.

O PL vigeu de 2005 a 2012 para os anos iniciais do ensino fundamental, tendo como objetivos: ancorar a ação pedagógica; incentivar reflexões e a construção de conhecimentos para a compreensão da linguagem e de seus processos de ensino e aprendizagem; criar a prática da formação continuada e ações que a possibilitassem, em parceria com universidades e rede pública de ensino (Brasil. MEC. SEB, 2012L). O processo formativo teve como principal material pedagógico um manual, com o conteúdo da formação presencial e a distância organizado em oito fascículos.

Já o Pnaic sucedeu ao PL em 2013, visando assegurar que todas as crianças estivessem alfabetizadas até os 8 anos de idade, ao final do terceiro ano do ensino fundamental. No período aqui estudado, almejavam-se:

[1] a compreensão do funcionamento do sistema de escrita; [2] o domínio das correspondências grafofônicas, ainda que nas poucas convenções ortográficas irregulares e nas poucas regularidades que exijam conhecimentos morfológicos mais complexos; [3] a fluência de leitura e o domínio de estratégias de compreensão e de produção de textos escritos (Brasil. MEC. SEB, 2012a, p. 8).

O material pedagógico do Pnaic constou de Cadernos de Formação para cada ano escolar. ${ }^{1}$

Empreendemos pesquisa documental (Yin, 2005) do Manual do PL e dos Cadernos do Pnaic em três etapas: 1) mapeamento de informações; 2) identificação de indicadores de fundamentos linguístico-epistemológicos; e 3) análise de excertos resultantes das etapas anteriores. O critério para formar o corpus nos fascículos do Manual do PL e nos Cadernos do Pnaic foi neles constarem explicitamente temas linguísticos, como ficará claro à frente. Por operarmos com filiação epistêmica e não discursiva (Lyotard, 2013; Saviani; Duarte, 2010), importam-nos conceitos (Vygotsky, 1982) que emergiram da análise, nomeados:

- Movimento A: enfoque linguístico cognitivo-sistêmico, desdobrado em Movimento A1: enfoque linguístico processual-sistêmico e Movimento A2: enfoque linguístico psicogenético-sistêmico; e

- Movimento B: enfoque linguístico na interação social, desdobrado em Movimento B1: enfoque linguístico histórico-cultural e Movimento B2: enfoque linguístico nos estudos do letramento.

Seguem, pois, duas seções: 1) teorização dos movimentos e 2) análise destes no âmbito dos programas.

\footnotetext{
${ }^{1}$ Transcende o foco deste artigo analisar materiais adicionais desses programas em outras mídias e/ou descrever sua operacionalização pedagógico-institucional.
} 


\section{Bases linguístico-epistemológicas dos programas}

Filiadas à Linguística, tratamos do objeto a partir de concepções de língua de Volóchinov $^{2}$ (2017): subjetivismo individualista, enfoque idealista/cognitivista; objetivismo abstrato, enfoque sistêmico-estrutural; e interação social, enfoque na historicidade intersubjetiva. No campo da alfabetização, porém, os enfoques puramente objetivista ou subjetivista não tendem a prevalecer. Concebemos, assim, a articulação de ambos, nomeada como enfoque cognitivista-sistêmico, o Movimento A, desdobrado em Movimento A1: enfoque linguístico processual-sistêmico e Movimento A2: enfoque linguístico psicogenético-sistêmico. Já a interação social, Movimento $B$, desdobra-se segundo a forma de conceber a cultura: como produto da atividade humana vital, o que nos leva a autores como L. S. Vygotsky e V. Volóchinov - e, em boa medida, também a M. Bakhtin -, e que nomeamos Movimento B1: enfoque linguístico histórico-cultural; e cultura vinculada a identidades culturais e multiculturalismo/pluralismo, que remete aos Estudos Culturais e implica o Movimento B2: enfoque linguístico nos estudos do letramento.

\subsection{Movimento A: enfoque linguístico cognitivista-sistêmico}

Enquanto o subjetivismo individualista foca o psiquismo individual, a atividade mental implicada no processamento da língua, o objetivismo abstrato foca o sistema linguístico estável de formas gramaticais e lexicais, na estrutura linguística (Volóchinov, 2017). Essas duas correntes tendem a se conjugar no campo da alfabetização, daí o mencionado Movimento A1: enfoque linguístico processualsistêmico, cuja tônica é o processamento cognitivo do sistema de escrita alfabética (SEA). O termo processual remete ao processamento neural/mental/cognitivo engendrado pelo SEA, do qual deriva o termo sistêmico, nele implicadas relações grafêmico-fonêmicas na leitura e fonêmico-grafêmicas na escritura, as quais são definidas pelo conceito estruturalista de valor (Saussure, 2012). Esse enfoque hoje se articula à Neurociência (Dehaene, 2012; Scliar-Cabral, 2013), mantendo a tradicional atenção à consciência fonológica/fonêmica (Libermann, 1973).

Já o Movimento A2: enfoque linguístico psicogenético-sistêmico referencia a abordagem psicogenética, considerando que, quando se estabelecem estágios implicacionais de desenvolvimento cognitivo, como em Ferreiro e Teberosky (1991), prevalece uma abordagem cognitivista - o subjetivismo de Volóchinov (2017); e quando esses estágios são estabelecidos na aprendizagem do sistema de escrita, tendo a sílaba e o fonema/grafema como bases, coloca-se a articulação com a dimensão sistêmica - o objetivismo do autor russo, daí a nomeação Movimento A2: enfoque linguístico psicogenético-sistêmico. Trata-se, pois, da psicogênese da apropriação da escrita, dadas as implicações cognitivas do SEA, a serviço da compreensão do percurso de mudança dos modos de os sujeitos operarem

\footnotetext{
${ }^{2}$ A grafia dos nomes russos segue as obras consultadas.
} 
cognitivamente com o objeto de conhecimento, já que a proposição da gradação nos mencionados níveis se ancora na lógica estrutural do sistema de escrita.

\subsection{Movimento B: enfoque linguístico na interação social}

Importam, aqui, duas vertentes teóricas convergentes, ao conceberem a língua como interação social, mantendo-nos em Volóchinov (2017). Distinguimo-las pela categoria que as funda: na primeira, que nomeamos Movimento B1: enfoque linguístico histórico-cultural, é fundante o trabalho (Volochínov, 2013); logo, a cultura é produto da atividade humana vital. Na segunda, que nomeamos Movimento B2: enfoque linguístico nos estudos do letramento, a cultura em si mesma é a categoria fundante, tomada como manifestação antropológica na diversidade dos grupos culturais (Street, 1984, 2000; Kalantzis; Cope, 2006), daí: culturas.

No Movimento B1: enfoque linguístico histórico-cultural, concebemos a língua na intersubjetividade, englobando - salvaguardadas as distinções - o quadro vygotskyano e o Círculo de Bakhtin; o foco é a vivificação da língua (Bakhtin, 2010) e, por extensão, da modalidade escrita, na enunciação. Assim, o processo de alfabetização prioriza a historicidade/eventicidade da interação social, estando o SEA a serviço delas, concebendo a cognição humana como implicação ontogenética para tal. Logo, o enfoque deixa de ser a articulação SEA/cognição - sob a ótica quer do processamento cognitivo, quer do movimento psicogenético delineado nele - para se colocar na interação social por meio da escrita. Toma-se o SEA como produto cultural, na historicidade viva, na qual as vozes sociais se encontram e, tão somente nesse âmbito, o conceito de gênero do discurso (Bakhtin, 2003) faz sentido.

Já no Movimento B2: enfoque linguístico nos estudos do letramento, focalizamse aspectos identitários da apropriação da escrita e busca-se compreender como as pessoas, alfabetizadas ou não, interagem pela escrita em diferentes esferas da atividade humana. Emerge a metáfora da ecologia (Barton, 2010), na atenção às formações culturais diferentes e ao modo como se valem da escrita. Aqui, os Estudos Culturais aportam o conceito de interação social, sob o fundamento do relativismo cultural, base do conceito de identidade e questões afins, confrontando hierarquizações culturais (Street, 1984, 2000) e negando a alfabetização como decodificação; os diferentes usos socioculturais da escrita são o tônus do processo educacional.

\section{PL e Pnaic: inferências sobre fundamentos linguístico- epistemológicos}

Apresentados os movimentos, passamos à abordagem documental para tratar das inferências linguístico-epistemológicas, restringindo-nos a um número de excertos tão somente básico para sustentar nossa argumentação. Em Abdala Martins (2017), consta análise exaustiva dos documentos, mas, aqui, a condição de "artigo" impede-nos de ir além de exemplos, os quais, no entanto, foram cuidadosamente 
pinçados de modo a ilustrar o todo dos documentos. Da simetria inferida em cada um desses quatro movimentos, no âmbito dos quais tomar um ou vários exemplos nada acrescentaria em força argumentativa, resultou a opção metodológica por não exibir os dados em quadros, colocando os dois movimentos lado a lado - o que favoreceria a comparação relacional do leitor -, mas no corpo das seções. Essa decisão decorre de, nos documentos, não haver tópicos que contribuam para uma comparação vis-a-vis, mas ocorrências que, sob diferentes tópicos, suscitam haver os quatro movimentos em ambos os programas.

Como a proposição dos Movimentos A e $B$ decorreu da análise documental, importa atenção a como esses movimentos se colocam na continuidade da formação, tendo presente que à esfera escolar não compete a ortodoxia teórica cara à esfera acadêmica. Logo, diferentes epistemologias coexistem naquela, o que, no entanto, não prescinde a esta última reconhecer incongruências filosóficas no percurso formativo, a exemplo de estar o Movimento A centrado na lógica do sistema de escrita integrada ao mentalismo do processamento cognitivo, enquanto o Movimento $B$ toma tais lógica e mentalismo como serviçais à intersubjetividade. Essas questões colocam os programas sob desafios de coerência epistemológica nem sempre fáceis de equacionar.

\subsection{Manual do Pró-Letramento, Alfabetização e Linguagem (PL): prevalência no Movimento B?}

No Manual do PL, priorizamos o Fascículo 1, em que questões linguísticas afetas à alfabetização se enunciam amplamente. A ele agregamos o Fascículo 4 - enfoque na biblioteca escolar, o Fascículo 7 - enfoque nas questões sociolinguísticas e o Fascículo Complementar - enfoque em vivências escolares que implicam gêneros do discurso. Ao cabo da análise, compreendemos haver uma tentativa desse programa de se ater ao Movimento B: enfoque linguístico na interação social, com presença mais efetiva do Movimento B1: enfoque linguístico histórico-cultural do que do Movimento B2: enfoque linguístico nos estudos do letramento, mas com a co-ocorrência, nem sempre coerente, do Movimento A: enfoque linguístico cognitivista-sistêmico, especialmente do Movimento A1: enfoque linguístico processual-sistêmico. O Movimento A2: enfoque linguístico psicogenético-sistêmico aparece apenas pontualmente, sem reiteração conceitual.

No Fascículo 1, encontramos o conteúdo que consta em [i] e [ii], em que há a assunção da língua como sistema a serviço da interação verbal; ao longo do Manual do PL, reitera-se a concepção de língua como interação social - Movimento B:

[i] A língua é um sistema que tem como centro a interação verbal, que se faz através de textos ou discursos, falados ou escritos. Isso significa que esse sistema depende da interlocução (inter + locução = ação linguística entre sujeitos). (Brasil. MEC. SEB, 2008 - Fascículo 1, p. 9).

[ii] Partindo dessa concepção, uma proposta de ensino de língua deve valorizar o uso da língua em diferentes situações ou contextos sociais, com sua diversidade de funções e sua variedade de estilos e modos de falar. Para estar de acordo com essa concepção, é importante que o trabalho em sala de aula se organize em torno do uso e que privilegie a reflexão dos alunos 
sobre as diferentes possibilidades de emprego da língua. (Brasil. MEC. SEB, 2008 - Fascículo 1, p. 9).

Aqui, o Movimento A: enfoque cognitivista sistêmico não é assumido como axial: atribui-se relevância ao Movimento A1: enfoque linguístico processualsistêmico e ao Movimento A2: enfoque linguístico psicogenético-sistêmico, mas como ingrediências, e não eixos do processo, como em [iii] - reconhecimento do Movimento A1; e em [iv] e [v] - reconhecimento do Movimento A2, sendo, em [iv], uma alusão à guisa de histórico e, em [v], uma aplicação dos níveis implicacionais psicogenéticos:

[iii] Historicamente, o conceito de alfabetização se identificou ao ensinoaprendizado da "tecnologia da escrita", quer dizer, do sistema alfabético de escrita, o que, em linhas gerais, significa, na leitura, a capacidade de decodificar os sinais gráficos, transformando-os em "sons", e, na escrita, a capacidade de codificar os sons da fala, transformando-os em sinais gráficos. (Brasil. MEC. SEB, 2008 - Fascículo 1, p. 10 - grifo do autor).

[iv] A partir dos anos 1980, o conceito de alfabetização foi ampliado com as contribuições dos estudos sobre a psicogênese da aquisição da língua escrita, particularmente com os trabalhos de Emilia Ferreiro e Ana Teberosky. De acordo com esses estudos, o aprendizado do sistema de escrita não se reduziria ao domínio de correspondências entre grafemas e fonemas (a decodificação e a codificação), mas se caracterizaria por um processo ativo por meio do qual a criança, desde os seus primeiros contatos com a escrita, construiria e reconstruiria hipóteses sobre a natureza e o funcionamento da língua escrita, compreendida como um sistema de representação. (Brasil. MEC. SEB, 2008 - Fascículo 1, p. 10 - grifo do autor).

[v] Várias questões pontuadas pela professora Karine podem servir de base para sua reflexão. Por exemplo: ao fazer aos alunos uma pergunta simples - o que poderiam fazer para lembrar de todos os nomes - ela desafiouos a refletir e a perceber que o registro escrito seria a única maneira de não se esquecerem dos nomes. Além de criar naquele momento uma necessidade real para a escrita dos nomes, a professora oportunizou às crianças vivenciarem a função social da escrita e entendê-la enquanto registro que pode extrapolar o tempo e o espaço. Por outro lado, ao propor aos alunos que escrevessem os nomes do "seu jeito", ela não só respeitou as hipóteses que eles provavelmente vinham construindo, como os incitou a pensar sobre a escrita: quantas e que letras usar, em que ordem e posição, como relacionar fonemas (sons) às respectivas letras. Em outros momentos, a professora propiciou aos alunos essa reflexão por meio do manuseio, pelas crianças, do alfabeto móvel [...] Afinal, como firma Teberosky (1989), escrever o próprio nome parece uma peça-chave para a criança começar a compreender o funcionamento do sistema de escrita. (Brasil. MEC. SEB, 2008 - Fascículo Complementar, p. 9-10 - grifo nosso).

Também o Movimento B2: enfoque linguístico nos estudos do letramento consta do documento - aliás, nomeia o próprio programa, no termo letramento, como pode ser observado a seguir:

[vi] Com o surgimento dos termos letramento e alfabetização (ou alfabetismo) funcional, muitos pesquisadores passaram a preferir distinguir alfabetização e letramento. Passaram a utilizar o termo alfabetização em seu sentido restrito, para designar o aprendizado inicial da leitura e da escrita, da natureza e do funcionamento do sistema de escrita. Passaram 
correspondentemente, a reservar os termos letramento ou, em alguns casos alfabetismo funcional para designar os usos (e as competências de uso) da língua escrita. Outros pesquisadores tendem a preferir utilizar apenas o termo alfabetização para significar tanto o domínio do sistema de escrita quanto os usos da língua escrita em práticas sociais. Nesse caso, quando sentem a necessidade de estabelecer distinções, tendem a utilizar as expressões "aprendizado do sistema de escrita" e "aprendizado da linguagem escrita". (Brasil. MEC. SEB, 2008 - Fascículo 1, p. 10 - grifo do autor).

Tal Movimento B2 surge também no Fascículo 7, associado ao conceito de gêneros do discurso, o que suscita o Movimento B1: enfoque linguístico históricocultural, e, como no excerto [vii], o conceito de evento de letramento (Heath, 2001) co-ocorre com o de iletramento, negado pelos próprios estudiosos do tema (Barton, 2010), dada a metáfora da ecologia e o multiculturalismo. Esse excerto ilustra uma controversa conjugação dos Movimentos B1 e B2: ao mesmo tempo que se reconhece a valoração da ideologia oficial (Volóchinov, 2017) de que trata o Movimento B1, ela é colocada em xeque, como exclusora, tal qual reza o multiculturalismo (Kalantzis; Cope, 2006) contido no Movimento B2.

[vii] De fato, a questão da inteligibilidade é complexa. Os brasileiros que têm pouca escolarização e consequentemente pouco contato com a cultura de letramento podem ter muita dificuldade para entender o discurso de um evento de letramento, como o de um jornal televisivo, uma entrevista de um político ou de um cientista na rádio ou na televisão. Essa dificuldade de entendimento tem de ser levada em consideração porque representa um forte entrave para a inclusão social da população iletrada em nosso país. (Brasil. MEC. SEB, 2008 - Fascículo 7, p. 16 - grifo nosso).

O Movimento B1: enfoque linguístico histórico-cultural é retomado em [viii], quando o conceito de gêneros do discurso - aqui sob a nomeação gênero textual afigura-se finalístico. Toma-se o sistema como "condicional" para o uso da escrita e como "inalterado" na mudança de gênero. Assumir o sistema como condição para o uso implica conceber este como consequência a que serve a "causa" sistêmica. Logo, reconhecer o uso sob o conceito de gênero suscita forte presença do Movimento B1.

[viii] A língua é um sistema que se estrutura no uso e para o uso, escrito e falado, sempre contextualizado. No entanto, a condição básica para o uso escrito da língua, que é a apropriação do sistema alfabético, envolve, da parte dos alunos, aprendizados muito específicos, independentes do contexto de uso, relativos aos componentes do sistema fonológico da língua e às suas inter-relações. Explicando e exemplificando: as relações entre consoantes e vogais, na fala e na escrita, permanecem as mesmas, independentemente do gênero textual em que aparecem e da esfera social em que circule [tal gênero]; numa piada ou nos autos de um processo jurídico, as consoantes e vogais são as mesmas e se inter-relacionam segundo as mesmas regras. (Brasil. MEC. SEB, 2008 - Fascículo 1, p. 11 - grifo nosso).

A prevalência do Movimento B: enfoque linguístico na interação social consta do Quadro 1, que apresenta o desenvolvimento de capacidades/habilidades previstas no PL, no qual inferimos a conjugação do Movimento B1: enfoque linguístico históricocultural - menção aos modos de produção e de circulação da escrita na sociedade - e do Movimento B2: enfoque linguístico nos estudos do letramento, com ênfase 
em usos/funções sociais da escrita, quase um "mantra" desses estudos (Kleiman, 1995; Street, 1984).

\section{Quadro 1 - Compreensão e valorização da cultura escrita: capacidades, conhecimentos e atitudes}

\begin{tabular}{|c|c|c|c|}
\hline Capacidades, conhecimentos e atitudes & $1^{\circ}$ ano & $2^{\circ}$ ano & $3^{\circ}$ ano \\
\hline $\begin{array}{l}\text { Conhecer, utilizar e valorizar os modos de produção e de } \\
\text { circulação da escrita na sociedade. }\end{array}$ & $\mathrm{I} / \mathrm{T} / \mathrm{C}$ & $\mathrm{T} / \mathrm{C}$ & $\mathrm{T} / \mathrm{C}$ \\
\hline Conhecer os usos e funções sociais da escrita & $\mathrm{I} / \mathrm{T} / \mathrm{C}$ & $\mathrm{T} / \mathrm{C}$ & $\mathrm{T} / \mathrm{C}$ \\
\hline Conhecer usos da escrita na cultura escolar & $\mathrm{I} / \mathrm{T} / \mathrm{C}$ & $\mathrm{T}$ & $\mathrm{R}$ \\
\hline $\begin{array}{l}\text { Desenvolver capacidades necessárias para o uso da escrita } \\
\text { no contexto escolar }\end{array}$ & $\mathrm{I} / \mathrm{T} / \mathrm{C}$ & $\mathrm{T}$ & $\mathrm{R}$ \\
\hline (i) saber usar objetos da escrita presentes na cultura escolar & $\mathrm{I} / \mathrm{T} / \mathrm{C}$ & $\mathrm{T}$ & $\mathrm{R}$ \\
\hline (ii) desenvolver capacidades específicas para escrever & $\mathrm{I} / \mathrm{T} / \mathrm{C}$ & $\mathrm{T}$ & $\mathrm{R}$ \\
\hline
\end{tabular}

Fonte: (Brasil. MEC. SEB, 2008 - Fascículo 1, p. 18)

Legenda: C - consolidar; I - introduzir; $\mathrm{R}$ - retomar; $\mathrm{T}$ - trabalhar sistematicamente.

Já a lógica do SEA vem na sequência, como segundo quadro - e não como primeiro -, em uma reiteração da servilidade causal do SEA ao uso; assim, o Movimento A1: enfoque linguístico processual-sistêmico é ratificado como constitutivo do processo de alfabetização, mas não como finalístico dele.

\section{Quadro 2 - Apropriação do sistema de escrita: capacidades, conhecimentos}

\begin{tabular}{|c|c|c|c|}
\hline Capacidades, conhecimentos e atitudes & $1^{\circ}$ ano & $2^{\circ}$ ano & $3^{\circ}$ ano \\
\hline $\begin{array}{l}\text { Compreender diferenças entre a escrita alfabética e outras } \\
\text { formas gráficas }\end{array}$ & $\mathrm{I} / \mathrm{T} / \mathrm{C}$ & $\mathrm{R}$ & $\mathrm{R}$ \\
\hline Dominar convenções gráficas & $\mathrm{I} / \mathrm{T} / \mathrm{C}$ & $\mathrm{R}$ & $\mathrm{R}$ \\
\hline $\begin{array}{l}\text { (i) Compreender a orientação e o alinhamento da escrita } \\
\text { da língua portuguesa }\end{array}$ & $\mathrm{I} / \mathrm{T} / \mathrm{C}$ & $\mathrm{R}$ & $\mathrm{R}$ \\
\hline $\begin{array}{l}\text { (ii) Compreender a função de segmentação dos espaços } \\
\text { em branco e da pontuação de final de frase }\end{array}$ & $\mathrm{I} / \mathrm{T} / \mathrm{C}$ & $\mathrm{R}$ & $\mathrm{R}$ \\
\hline $\begin{array}{l}\text { Reconhecer unidades fonoaudiológicas como sílabas, rimas, } \\
\text { terminações de palavras, etc. }\end{array}$ & $\mathrm{I} / \mathrm{T} / \mathrm{C}$ & $\mathrm{T}$ & $\mathrm{R}$ \\
\hline Conhecer o alfabeto & $\mathrm{I} / \mathrm{T}$ & $\mathrm{T} / \mathrm{C}$ & $\mathrm{R}$ \\
\hline $\begin{array}{l}\text { (i) Compreender a categorização gráfica e funcional das } \\
\text { letras }\end{array}$ & $\mathrm{I} / \mathrm{T}$ & $\mathrm{T} / \mathrm{C}$ & $\mathrm{R}$ \\
\hline $\begin{array}{l}\text { (ii) Conhecer e utilizar os diferentes tipos de letras (de } \\
\text { fôrma e cursiva) }\end{array}$ & $\mathrm{I} / \mathrm{T}$ & $\mathrm{T} / \mathrm{C}$ & $\mathrm{R}$ \\
\hline Compreender a natureza alfabética do sistema de escrita & $\mathrm{I} / \mathrm{T}$ & $\mathrm{T} / \mathrm{C}$ & $\mathrm{R}$ \\
\hline Dominar as relações entre grafemas e fonemas & I & $\mathrm{T} / \mathrm{C}$ & $\mathrm{T} / \mathrm{C}$ \\
\hline (i) Dominar regularidades ortográficas & I & $\mathrm{T} / \mathrm{C}$ & $\mathrm{T} / \mathrm{C}$ \\
\hline (ii) Dominar irregularidades ortográficas & I & $\mathrm{I} / \mathrm{T}$ & $\mathrm{T} / \mathrm{C}$ \\
\hline
\end{tabular}

Fonte: Brasil. MEC. SEB (2008 - Fascículo 1, p. 24).

Legenda: C - consolidar; I - introduzir; $\mathrm{R}$ - retomar; $\mathrm{T}$ - trabalhar sistematicamente.

A servilidade processual-sistêmica à interação social reitera-se também em [ix], que endossa a forte presença do Movimento B1: enfoque linguístico históricocultural no PL, a ponto de admitir a vivência da textualização como anterior ao domínio processual-sistêmico - e, por implicação, dissociada dele -, ainda que em nome de tomá-lo como necessariamente "progressivo": 
[ix] A leitura e a produção escrita, [...], seriam atividades que exigiriam o domínio do sistema ortográfico de escrita. No entanto, é possível ler e escrever pequenos textos, com autonomia ou ajuda do professor ou da professora, mesmo antes de ter domínio do sistema de escrita.

Por exemplo, na situação de escrever listas úteis de nomes, de objetos ou de decisões, etiquetas que servirão para organizar a sala de aula, pequenos avisos, etc., o aluno se vê desafiado a grafar as palavras que quer empregar e isso provoca a necessidade de refletir e formular hipóteses sobre como cada fonema e cada sílaba pode ser representado na escrita. A criança terá então que se esforçar para distinguir os fonemas que compõem tais palavras e descobrir possibilidades coerentes de escrever os "sons" identificados, apoiando-se nos princípios e regularidades que já tiver apreendido, mas também buscando soluções inéditas.

\section{$[\ldots]$}

Adotar um princípio de progressão não significa impedir os alunos de ver o que ainda não está na ordem prevista nem deixar de responder a perguntas deles sobre conteúdos planejados para serem tratados posteriormente. O contato dos alunos com textos autênticos e a produção escrita espontânea, em muitas ocasiões, podem estimular discussões sobre relações fonemagrafema, mesmo que estas não sejam aprofundadas naquele momento. (Brasil. MEC. SEB, 2008 - Fascículo 1, p. 34 - grifo do autor).

Finalmente, em [x], a reiteração do Movimento B1: enfoque linguístico histórico-cultural é inconteste, a despeito de o conceito de gênero do discurso colocar-se sob o aplanamento epistemológico do conceito de gênero textual, ${ }^{3}$ focado na dimensão estrutural dos gêneros.

[x] Identificar finalidades e funções da leitura, em função do reconhecimento do suporte, do gênero e da contextualização do texto

Para contribuir com o desenvolvimento da capacidade dos alunos de ler com compreensão, é importante que o professor ou a professora lhes proporcione a familiaridade com gêneros textuais diversos (histórias, poemas, trovas, canções, parlendas, listas, agendas, propagandas, notícias, cartazes, receitas culinárias, instruções de jogos, regulamentos), lendo para eles em voz alta ou pedindo-lhes leitura autônoma. Além disso, é desejável abordar as características gerais desses gêneros (do que eles costumam tratar, como costumam se organizar, que recursos linguísticos costumam usar, para que servem). A capacidade de reconhecer diferentes gêneros textuais e identificar suas características gerais favorece bastante o trabalho de compreensão, porque orienta adequadamente as expectativas do leitor diante do texto. (Brasil. MEC. SEB, 2008 - Fascículo 1, p. 44 - grifo do autor).

Se, porém, nos Fascículos 1, 7 e Complementar do Manual do PL, inferimos reiteração do Movimento B1: enfoque linguístico histórico-cultural, no Fascículo 4 , com enfoque na biblioteca escolar, elicia-se o Movimento A1: enfoque linguístico processual-sistêmico - [xi] e [xii] -, dado que o conceito de leitura é tomado na abstração processual, sob o cognitivismo subjetivista, leitura como intransitiva (Britto, 2015): "ler" sem haver complemento para esse verbo, o que é incompatível com o

\footnotetext{
${ }^{3}$ Entendemos que o conceito de gênero textual/gênero de texto reduz o alcance filosófico-epistemológico do conceito de gênero do discurso: a materialidade textual é constitutiva do gênero, mas ele não se reduz a ela (Bakhtin, 2010).
} 
conceito de gênero do discurso (Bakhtin, 2003), à égide do qual o verbo "ler" nunca será intransitivo. Lemos um texto historiado em um gênero do discurso específico. Essa tomada intransitiva remete à tradição processual cognitiva da leitura, apesar de menção pontual a gêneros textuais e a alguns exemplos finais respectivos a eles, no bojo dos quais há confusão entre portadores de texto ("revista", por exemplo) e gêneros:

[xi] Como temos visto, muitas histórias de leituras de leitores experientes revelam que seu sucesso se deve a uma prática mais ampla de leitura. Eles foram expostos a diversas situações: escutaram histórias na infância, criaram histórias a partir das ilustrações nos livros, leram sozinhos, leram também com colegas e professores(as), em silêncio e em voz alta, compartilharam leituras em casa, na escola e na vida. Também tiveram contato com diversos materiais escritos: Bíblia, jornais, revistas, livros infantis, gibis, lista telefônica, dicionários. (Brasil. MEC. SEB, 2008 Fascículo 4, p. 29).

[xii] É fundamental que os alunos vivenciem diversas situações de leitura. Nesse sentido, a leitura deve fazer parte do projeto pedagógico da escola, envolver toda a comunidade escolar, e ser a sua prioridade número 1. Você, melhor do que ninguém, conhece seus alunos e sabe os assuntos de maior interesse para eles. Leia bastante para seus alunos e procure envolvê-los com um ritmo adequado, uma entonação caprichada e compatível com o gênero textual, usando todos os recursos possíveis para cativar seus ouvintes. Além de você, o aluno também precisa ler para os colegas.

Depois de ouvir você ou o colega ler em voz alta, para que essa leitura faça sentido na vida dos alunos, seria interessante todos comentarem sobre o que ouviram, que sentido aquilo teve para cada um. Se houver diferenças de interpretação, é interessante discutir os argumentos, com a sua mediação, para negociar os sentidos do texto. Um mesmo texto pode ser entendido de diversas maneiras por diferentes leitores, mas há limites para a liberdade de intepretação. (Brasil. MEC. SEB, 2008 - Fascículo 4, p. 30).

Essa entrada processual-sistêmica da leitura tomada intransitivamente, ao gosto do cognitivismo da década de 1980, aparece também, embora pontualmente apenas, no Fascículo Complementar, no qual entendemos prevalecer o Movimento B1: enfoque histórico-cultural. Esse prevalecendo, as estratégias de leitura teriam, porém, de ser tratadas no âmbito da interação social respectivamente ao gênero do discurso, isso porque as estratégias cognitivas agenciadas para as diferentes interações nos diferentes gêneros seguramente são distintas, não podendo ser tomadas na abstração processual-sistêmico-textual. Segue [xiii], com a inferida incongruência:

[xiii] Estratégias de leitura

Para Soares (1998), dentre outras habilidades/capacidades, a leitura inclui as de fazer previsões sobre o texto, de construir significado combinando conhecimento prévio e informação textual, de refletir sobre o significado do que foi lido e tirar conclusões sobre o assunto enfocado. Por outro lado, essas habilidades/capacidades são desenvolvidas à medida que o leitor, no ato de ler, faz uso das chamadas estratégias de leitura. [...]. (Brasil. MEC. SEB, 2008 - Fascículo Complementar, p. 21). 
Nesse âmbito, compreendemos que o Manual do PL conjuga uma busca pela consolidação do Movimento B: enfoque linguístico na interação social, sublinhando a interação social como concepção de língua, ainda que haja pontualidades cognitivistas como as que mencionamos aqui. Nisso, o Movimento B1: enfoque linguístico histórico-cultural se sobressai, especialmente pelas reiteradas alusões ao conceito de gênero, ainda que se repliquem indissociações entre gênero e "portadores de textos", no aplanamento conceitual gênero textual/gênero de texto. A interação social aparece também nas discussões sobre "variação linguística" no Fascículo 7, suscitando, todavia, a vertente laboviana, para a qual, como adverte Faraco (2001), a historicidade das relações sociais é preterida em favor das categorias quantitativas às quais pertencem os interactantes. Trata-se, pois, de distanciamentos dos fundamentos efetivos do Movimento B1. E, adicionalmente, em que pese o "letramento" nomear esse programa, entendemos haver tão somente menções ocasionais ao Movimento B2: enfoque linguístico nos estudos do letramento; não nos parece que as bases dos Estudos Culturais sejam fundamentos efetivos do documento, que, por exemplo, menciona conceitos como iletrado (Brasil. MEC. SEB, 2008 - Fascículo 7, p. 16) e níveis de letramento (Brasil. MEC. SEB, 2008 - Fascículo 1, p. 11), os quais são amplamente denegados por estudiosos fundadores dessa vertente (Barton, 2010; Street, 1984, 2000).

Quanto ao Movimento A: enfoque linguístico cognitivista-sistêmico, entendemos haver, no Fascículo 1 e no Fascículo Complementar, ratificação da servilidade do sistema aos usos da escrita; no entanto, no Fascículo 4, a concepção intransitiva de leitura assenta-se fundamentalmente no Movimento A1: enfoque linguístico processualsistêmico. Assim, reiteramos que o PL sublinha a alfabetização com base em uma concepção de língua como interação social - Movimento B, mas possivelmente a natureza plural de seu processo de produção, no que tange à autoria, visibilize esses diferentes movimentos, que não nos parecem integrados - tal qual seria justificado ocorrer na esfera escolar -, mas justapostos e, nessa condição, conflituados.

\subsection{Cadernos de Formação do Pnaic: sublinhas no Movimento A?}

Se, no PL, prevalecem confluências do Movimento B: enfoque linguístico na interação social, no Pnaic inferimos coexistência dos diferentes movimentos, com maior proeminência do Movimento A: enfoque linguístico cognitivista-sistêmico, ${ }^{4}$ de modo que as menções ao Movimento B: enfoque linguístico na interação social se atêm a necessário "pano de fundo", prevalecendo o processamento cognitivo e a configuração sistêmica da alfabetização. Nessa coexistência, as bases do Movimento B1: enfoque linguístico histórico-cultural e do Movimento A2: enfoque linguístico

\footnotetext{
${ }^{4}$ Não quantificamos ocorrências de tais movimentos, abordagem matemática distinta deste artigo. Ilustramos numericamente nos excertos o que entendemos ser recorrente, a indiciar prevalências mais ou menos efetivas deles.
} 
psicogenético-sistêmico se anunciam no Pnaic em alusão inicial a Lev Vygotsky e a Jean Piaget - [xiv] - e, em [xv], [xvi] e [xvii], assume-se, de modo mais amplo, a busca pela integração do Movimento A e do Movimento B:

[xiv] Diferentes autores [...] defendem que a aprendizagem ocorre por meio da atividade do sujeito aprendiz. Segundo Piaget, "o indivíduo não poderia organizar suas operações num todo coerente se ele não se engajasse nas trocas e cooperação com o outro" (1973, p. 163). Desse modo, o aprendiz é ativo, pois constroi aprendizagens, tendo, com isso, a participação de outras pessoas, com as quais interage. Vygotsky (1989a), assim como Piaget, também destaca o papel da interação do aprendiz com o outro no processo de aprendizagem, mas enfatiza a dimensão da cultura nessa interação. (Brasil. MEC. SEB, 2012h, p. 13 - Unidade 1/Ano 3).

[xv] É preciso que fique claro, de antemão, que não há nenhuma oposição entre propor um ensino sistemático do SEA e desenvolver práticas de leitura e produção de textos de diferentes gêneros em sala de aula. Ao defendermos uma concepção de alfabetização em uma perspectiva de letramento, compreendemos, assim como Soares (1998), que tanto as atividades de reflexão sobre o SEA e suas convenções, quanto as práticas de uso social da leitura e da escrita devem estar presentes em sala de aula, mesmo antes de a criança ter aprendido a ler e escrever convencionalmente. (Brasil. MEC. SEB, 2012f, p. 20 - Unidade 3/Ano 2).

[xvi] A partir da proposta de "alfabetizar letrando", os docentes devem levar as crianças à apropriação do Sistema de Escrita Alfabética (SEA) [...] em situações de uso social da escrita, desenvolvendo a capacidade de ler e produzir textos com finalidades distintas. Assim, o contato com a diversidade de gêneros e as situações de leitura e produção de textos deve acontecer de forma simultânea ao processo de aprendizado do SEA. (Brasil. MEC. SEB, 2012j, p. 6 - Unidade 3/Ano 3).

No decurso dos Cadernos de Formação, no entanto, abrem-se mais espaços para o Movimento A2: enfoque linguístico psicogenético-sistêmico, como nos excertos seguintes, dos quais [xvii] e [xviii] são icônicos, porque alçam a psicogênese à condição de concepção de língua; já [xix] e [xx], assim como as Figuras 1 e $2,{ }^{5}$ marcam os conhecidos níveis implicacionais de aprendizagem da escrita:

[xvii] Na década de 1980, as práticas de alfabetização baseadas em métodos sintéticos e analíticos [...] passaram a ser amplamente criticadas à luz de teorias construtivistas e interacionistas de ensino (em geral) e da língua (em particular). No campo da alfabetização, os trabalhos de Emília Ferreiro e Ana Teberosky sobre a Psicogênese da Língua Escrita [...] vão influenciar no desenvolvimento de novas práticas de alfabetização. Demonstrando que a escrita alfabética não era um código, o qual se aprenderia a partir de atividades de repetição e memorização, as autoras propuseram uma concepção de língua escrita como um sistema de notação que, no nosso caso, é alfabético. (Brasil. MEC. SEB, 2012b, p. 16 - Unidade 1/Ano 1 grifo nosso).

[xviii] O rompimento da concepção de língua escrita como código para uma concepção da mesma como sistema de notação alfabética, realizado por meio de diversos estudos, entre eles, os de Emília Ferreiro e Ana Teberosky (1986), trouxe avanços significativos para o fazer pedagógico. (Brasil. MEC. SEB, 2012e, p. 7 - Unidade 5/Ano 1 - grifo nosso).

\footnotetext{
${ }^{5} \mathrm{Na}$ Figura 2, mantivemos apenas fragmento da imagem original, dado o foco do presente argumento.
} 
[xix] Hipóteses infantis segundo a psicogênese da escrita

Hipótese pré-silábica: a criança ainda não compreende que existe relação entre a escrita e a pauta sonora, podendo usar letras, pseudoletras, números, rabiscos e até mesmo desenhos para escrever; [...]

Hipótese silábica: a criança estabelece uma correspondência entre a quantidade de letras utilizadas e a quantidade de sílabas orais das palavras, podendo usar letras com ou sem valor sonoro convencional; [...]

Hipótese silábico-alfabética: a criança começa a perceber que uma única letra não é suficiente para registrar as sílabas e recorre, simultaneamente, às hipóteses silábica e alfabética; [...]

Hipótese alfabética: a criança compreende que se escreve com base em uma correspondência entre sons menores que as sílabas (fonemas) e grafemas [...]. (Brasil. MEC. SEB, 2012f, p. 8 - Unidade 3/Ano 2 - grifos do autor). ${ }^{6}$

[xx] O percurso que as crianças vivem, para poder compreender o SEA

Quando acompanhamos, cuidadosamente, a evolução da escrita espontânea das crianças, vemos que elas elaboram hipóteses semelhantes, descobertas por Ferreiro e Teberosky (1986). Sim, é preciso deixar as crianças escreverem como sabem (e não só copiarem palavras escritas corretamente pela professora), para podermos detectar em que nível de compreensão de nosso sistema alfabético o menino ou a menina se encontram.

Conforme a teoria da psicogênese da escrita, elaborada por Ferreiro e Teberosky, os aprendizes passam por quatro períodos nos quais têm diferentes hipóteses ou explicações para como a escrita alfabética funciona: pré-silábico, silábico, silábico-alfabético e alfabético. (Brasil. MEC. SEB, 2012d, p. 11 - Unidade 3/Ano 1 - grifo do autor).
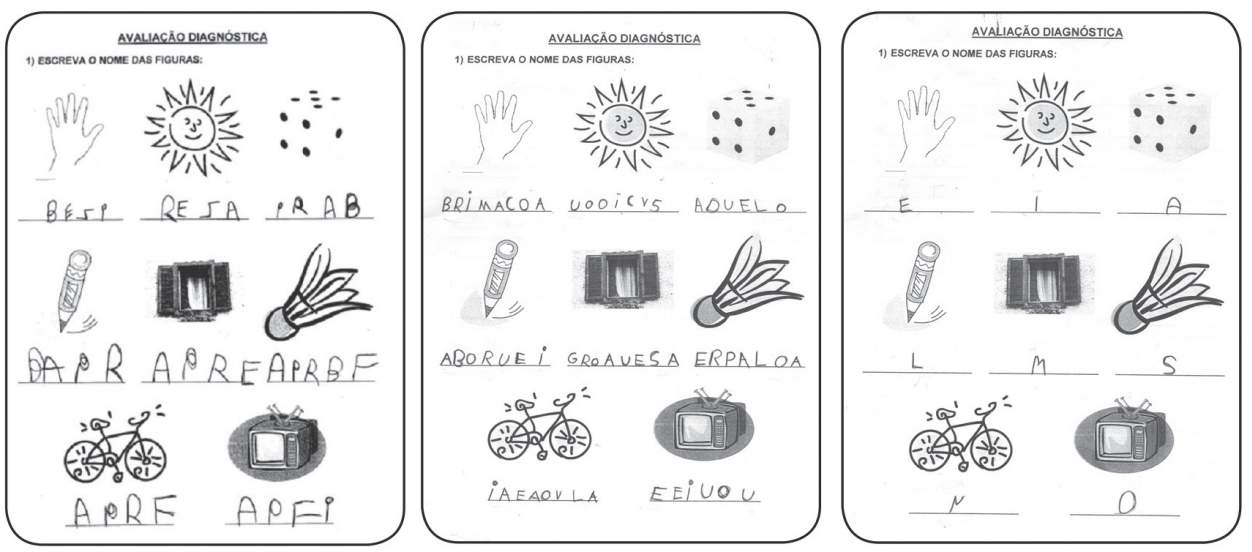

Figura 1 - Exemplos de escritas de crianças com hipóteses pré-silábicas

Fonte: Brasil. MEC. SEB (2012d, p. 12 - Unidade 2/Ano 1).

\footnotetext{
${ }^{6}$ Elidimos boa parte da transcrição do conteúdo atinente à descrição de cada hipótese, dado tratar-se de um tema bastante conhecido e considerando que o objetivo da presente transcrição é tão somente marcar a reiterada menção a essa abordagem no Pnaic.
} 


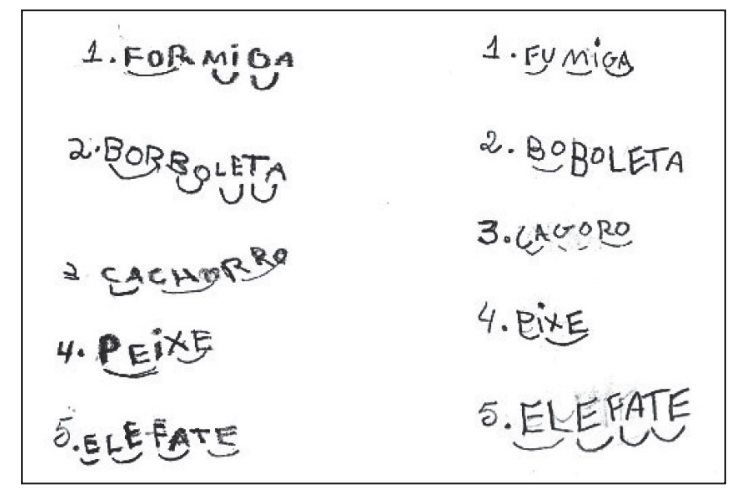

\section{Figura 2 - Exemplos de escritas de alunos [...] com hipóteses alfabéticas}

Fonte: Brasil. MEC, SEB (2012f, p. 14 - Unidade 3/Ano 2).

Quanto ao Movimento A1: enfoque linguístico processual-sistêmico, ele também é recorrente - ainda que em menor proporção que o Movimento A2: enfoque linguístico psicogenético-sistêmico, conforme os excertos a seguir - o primeiro deles focado na lógica do SEA, os demais na consciência fonológica.

[xxi] Quando falamos sobre ensino da ortografia no ano 3, estamos nos referindo à necessidade de chamar a atenção dos alunos para algumas relações som-grafia presentes na norma. Algumas daquelas relações já vão se estabelecendo durante a apropriação do SEA. Antes de nos dedicarmos ao ensino que reflete sobre determinadas regularidades ortográficas, é necessário compreender como a norma ortográfica do português está constituída.

Nossa norma ortográfica apresenta casos de regularidades e irregularidades na relação entre sons e letras.

As correspondências regulares podem ser de três tipos: diretas, contextuais e morfológico-gramaticais. A apropriação dessas restrições se dá através da compreensão dos princípios gerativos da norma, isto é, das regras.

As correspondências irregulares, por outro lado, não apresentam uma regra que ajude o aprendiz a selecionar a letra ou o dígrafo que deverá ser usado. Apenas um dicionário ou a memorização poderá ajudar nesses casos [...].

As regularidades diretas são evidenciadas quando só existe na língua um grafema para notar determinado fonema (é o caso de P, B, T, D, F, V). (Brasil. MEC. SEB, 2012j, p. 20 - Unidade 3/Ano 3 - grifo do autor).

[xxii] O papel de certas habilidades de consciência fonológica na apropriação do SEA

Desde a década de 1970, pesquisas feitas em diversos países vêm demonstrando que existe uma relação entre o que se passou a chamar consciência fonológica e o aprendizado da escrita alfabética. Mas, afinal, o que é consciência fonológica?

Sabemos, hoje, que a consciência fonológica é um vasto conjunto de habilidades que nos permitem refletir sobre as partes sonoras das palavras [...]. Sim, além de usarmos as palavras para nos comunicar, podemos assumir diante delas uma atitude metacognitiva, refletindo sobre sua dimensão sonora. (Brasil. MEC. SEB, 2012d, p. 20 - Unidade 3/Ano 1 - grifo do autor). 
[xxiii] A consciência fonológica e sua relação com o processo de compreensão do Sistema de Escrita Alfabética e de sua consolidação

Tanto para o processo de apropriação do SEA como para a consolidação do conhecimento das correspondências som-grafia, o desenvolvimento de habilidades de reflexão fonológica (consciência fonológica) é importante. O que é, então, consciência fonológica? A consciência fonológica consiste na capacidade de refletir conscientemente sobre as unidades sonoras das palavras e de manipulá-las de modo intencional [...]. Essa capacidade não é constituída por uma única habilidade, que a criança teria ou não, mas por um conjunto de habilidades distintas, que se desenvolveriam em momentos diferentes [...]. (Brasil. MEC. SEB, 2012f, p. 9 - Unidade 3/Ano 2 - grifo do autor).

[xxiv] Atividades envolvendo a consciência fonológica

A consciência fonológica é um conjunto de habilidades metalinguísticas que permitem ao indivíduo refletir sobre os segmentos sonoros das palavras em diferentes níveis: silábico, intra-silábico e fonêmico. Segundo Gombert (2003), as atividades metalinguísticas são atividades de reflexão sobre a linguagem e sobre seu uso. Consistem na capacidade do sujeito monitorar intencionalmente e planejar os métodos próprios do processamento linguístico (compreensão e produção). Tais habilidades abrangem alguns aspectos específicos da língua, no nosso caso nos deteremos nas habilidades metafonológicas ou consciência fonológica.

As atividades que envolvem a reflexão fonológica auxiliam tanto os alunos que ainda não compreenderam que existe relação entre escrita e pauta sonora, isto é, não perceberam o que a escrita representa, como os alunos que já compreenderam o princípio alfabético da escrita, mas apresentam dificuldades em estabelecer relação som-grafia. Para esse último grupo, foco deste caderno, sugerimos [...] atividades, envolvendo a consciência fonológica. (Brasil. MEC. SEB, 2012j, p. 11 - Unidade 3/ Ano 3 - grifo do autor)

Tal coexistência dos movimentos implica, ainda, menções ao Movimento B1: enfoque linguístico histórico-cultural, como se observa em [xxv], mantendo-se, porém, no já comentado conceito de gênero textual, tônus marcadamente estrutural na formatação dos gêneros (Geraldi, 2010). Nesse excerto, inferimos a tomada destes mais como "direito de aprendizagem" do que como implicação de concepção de língua:

[xxv] É com base nestas ideias que tomamos os usos dos gêneros textuais como ponto de partida para a prática pedagógica, com o objetivo primeiro de propiciar a vivência destas práticas também em ambiente escolar e despertar nossos alunos para o uso além dos muros da escola. Ensinar por meio dos usos dos gêneros textuais significa promover um ensino voltado para a vida, que propicie verdadeiramente a formação do cidadão participativo das práticas sociais que envolvem a cultura escrita. É um direito de nossos alunos e cabe aos professores garantir este direito de aprendizagem a cada um. (Brasil. MEC. SEB, 2012c, p. 8 - Unidade 2/ Ano 1 - grifo nosso).

Isso se reitera em [xxvi], cujo conteúdo se mantém no conceito de gêneros textuais, em que pese a citação explícita a M. Bakhtin, filósofo contraporte do "ensinar gêneros", como adverte Geraldi (2010). Registramos, adicionalmente, a controversa nomeação sociointeracionista, epistemologicamente redutora da 
[xxvi] Por que ensinar gêneros textuais na escola?

[...]. Nessas atividades, convergem de forma indissociável fatores linguísticos, sociais e culturais. Nelas, os interlocutores são participantes de um processo de interação, e, para isso, precisam ter domínio da mesma língua e compartilharem as situações e as formas como os discursos se organizam, considerando seus propósitos de usos e os diversos contextos sociais e culturais em que estão inseridos. [...]

Nesse sentido, a língua se configura como uma forma de ação social, situada num contexto histórico, representando algo do mundo real. O texto, portanto, não é uma construção fixa e abstrata, mas, sim, palco de negociações e produções de múltiplos sentidos. Os textos são produzidos em situações marcadas pela cultura e assumem formas e estilos próprios, também historicamente marcados. Diferentes textos assemelham-se, como diz Bakhtin (1997), porque se configuram segundo características dos gêneros textuais que estão disponíveis nas interações sociais. Desse modo, pode-se dizer que a comunicação verbal só é possível por meio de algum gênero que se materializa em textos que assumem formas variadas para atender a propósitos diversos. Para melhor entendermos essa discussão, é importante enfocar as diferenças entre gêneros textuais e tipos textuais. (Brasil. MEC. SEB, 2012g, p. 6 - Unidade 5/Ano2 - grifo do autor).

Esse enfoque textual dos gêneros se reitera em [xxvii], explicitando a Escola de Genebra (Dolz; Schneuwly, 2004), em uma abordagem estrutural do conceito (Geraldi, 2010). Assim, como no excerto imediatamente anterior, teríamos o Movimento B1: enfoque linguístico histórico-cultural tomado sob a prevalência estrutural que essa escola parece nele alocar, o que suscita incoerência epistemológica.

[xxvii] Os gêneros textuais, segundo Schneuwly e Dolz (2004), são instrumentos culturais disponíveis nas interações sociais. São historicamente mutáveis e relativamente estáveis. Emergem em diferentes domínios discursivos e se concretizam em textos, que são singulares.

Assim, para que a interação entre falantes aconteça, cada sociedade traz consigo um legado de gêneros, por meio dos quais são partilhados conhecimentos comuns. Em consequência das mudanças sociais, os gêneros se alteram, desaparecem, se transformam em outros gêneros. (Brasil. MEC. SEB, 2012g, p. 7 - Unidade 5/Ano 2).

Na sequência, a menção conceitual muda, surgem os gêneros discursivos, e M. Bakhtin é referenciado, reinstanciando-se incongruências teóricas, dada a substantiva diferença entre os fundamentos da Escola de Genebra e os do Círculo de Bakhtin (Geraldi, 2010). Segue [xxviii] com ambas as vertentes lado a lado:

[xxviii] Os gêneros textuais, segundo Schneuwly e Dolz (2004), são instrumentos culturais disponíveis nas interações sociais. São historicamente mutáveis e relativamente estáveis. Emergem em diferentes domínios discursivos e se concretizam em textos, que são singulares.

Assim, para que a interação entre falantes aconteça, cada sociedade traz consigo um legado de gêneros, por meio dos quais são partilhados conhecimentos comuns. Em consequência das mudanças sociais, os gêneros se alteram, desaparecem, se transformam em outros gêneros. 
Desse modo, novos gêneros textuais vão se constituindo, em um processo permanente, em função de novas atividades sociais. [...] Segundo Bakhtin, (1997, p. 302):

"Aprendemos a moldar nossa fala às formas do gênero e, ao ouvir a fala do outro, sabemos de imediato, bem nas primeiras palavras, pressentirlhe o gênero, adivinhar-lhe o volume (a extensão aproximada do todo discursivo), a dada estrutura composicional, prever-lhe o fim. (...) Se não existissem os gêneros do discurso e se não os dominássemos, se tivéssemos de construir cada um de nossos enunciados, a comunicação verbal seria quase impossível."

Observamos que para Bakhtin (1997), os gêneros exercem certo efeito normativo. (Brasil. MEC. SEB, 2012g, p. 7 - Unidade 5/Ano 2-grifo nosso).

Também o Movimento B2: enfoque linguístico nos estudos do letramento se marca ao longo dos Cadernos de Formação como estando "em perspectiva", sem constituir efetivamente uma ancoragem epistemológica, o que é ilustrado nos excertos a seguir:

[xxix] O discurso da importância de se considerar os usos e funções da escrita com base no desenvolvimento de atividades significativas de leitura e escrita na escola foi incorporado, principalmente a partir da década de 90, a um novo conceito de alfabetização: o de letramento. (Brasil. MEC. SEB, 2012b, p. 17 - Unidade 1/Ano 1).

[xxx] Como poderá ser observado, durante a leitura deste material, todo o trabalho com a alfabetização na perspectiva do letramento está pautado na busca da realização de atividades que levem em consideração os usos sociais da língua escrita, não somente os escolares, mas também os relativos a outras esferas sociais. (Brasil. MEC. SEB, 2012c, p. 7 Unidade 2/Ano 1).

Colocam-se, nesse enfoque, distinções e aproximações entre letramento e alfabetização, muito discutidas no Brasil há alguns anos (Kleiman, 1995; Soares 1998). Nesse propósito, sublinha-se o zelo em se evitar o espontaneísmo, argumentando-se que a mera exposição aos usos da escrita não assegura o processo de alfabetização, o que suscita o conteúdo de [xxxi]:

[xxxi] Por outro lado, é importante destacar que apenas a interação com textos que circulam na sociedade não garante que os alunos se apropriem da escrita alfabética, uma vez que, no geral, essa aprendizagem não acontece de forma espontânea, mas exige um trabalho de reflexão sobre as características do nosso sistema de escrita. (Brasil. MEC. SEB, 2012b, p. 18 - Unidade 1/Ano 1).

Assim, o SEA, também em sua dimensão processual, é posto em conjugação com o conceito de letramento, numa articulação dos Movimentos A e B; o que é letramento aparece na Unidade 3 do ano 1, como mostra [xxxii], quando se integram os Movimentos B2: enfoque linguístico nos estudos do letramento e B1: enfoque linguístico histórico-cultural, na evocação aos gêneros:

[xxxii] Afinal, o que é LETRAMENTO?

Embora saibamos que, hoje, letramento é um conceito complexo e multifacetado, ao pensarmos no processo de alfabetização e de 
ensino-aprendizagem da escrita na escola, concebemos letramento como o conjunto de práticas de leitura e produção de textos escritos que as pessoas realizam em nossa sociedade, nas diferentes situações cotidianas formais e informais. Nessas situações, os gêneros textuais são incrivelmente variados e cada um deles tem características próprias quanto à estrutura composicional, quanto aos recursos linguísticos que usa, bem como quanto às finalidades para que é usado e aos espaços onde circula. Como Magda Soares (1998) e outros estudiosos, consideramos perfeitamente possível e adequado alfabetizar letrando, isto é, ensinar o SEA, permitindo que os aprendizes vivam práticas de leitura e de produção de textos, nas quais vão incorporando aqueles conhecimentos sobre a língua escrita. (Brasil. MEC. SEB, 2012d, p. 7 - Unidade 3/Ano 1 - grifo do autor)

Retornando, enfim, ao Movimento A1: enfoque linguístico processualsistêmico, em [xxxiii], suscitam-se dois processos caros aos estudos cognitivistas da leitura: "capacidade" e "atividade" de leitura (Morais, 1996):

[xxxiii] A leitura envolve a aprendizagem de diferentes habilidades, tais como: (i) o domínio da mecânica que implica na transformação dos signos escritos em informações, (ii) a compreensão das informações explícitas e implícitas do texto lido e (iii) a construção de sentidos. As referidas habilidades inter-relacionam-se e não podem ser pensadas hierarquicamente. (Brasil. MEC. SEB, 2012c, p. 8 - Unidade 2/ Ano 1).

Assim, ainda que, por restrições do gênero artigo, tenhamos abreviado a análise documental presente em Abdala Martins (2017), sustentamos haver, nos Cadernos do Pnaic focalizados, a presença de todos os movimentos de que nos ocupamos na primeira seção deste estudo. Porém, enquanto constaria no PL uma busca por marcar os fascículos, de algum modo, pela ênfase na interação social ainda que entendamos se tratar de uma concepção de interação social bastante fluida entre o Movimento B1: enfoque linguístico histórico-cultural e o Movimento B2: enfoque linguístico nos estudos do letramento -, inferimos constar dos Cadernos de Formação do Pnaic uma sublinha mais efetiva no Movimento A2: enfoque linguístico psicogenético-sistêmico. Entendemos que os conteúdos com maior consistência argumentativa e maior coerência teórica foram exatamente aqueles afetos ao Movimento A2, caracterizando-se por substantivo zelo conceitual e adequação epistemológica.

Quando, porém, os Cadernos tematizam o Movimento B: enfoque linguístico na interação social, tanto a consistência argumentativa quanto a coerência teórica se fragilizam, havendo pulverizações conceituais, como no conceito de gêneros e na abordagem apenas pontual do conceito de letramento: talvez mais que isso, tratandose do conceito de gêneros, indiciam-se incongruências epistemológicas, como procuramos mostrar ao longo desta seção, apontando a múltipla autoria dos materiais pedagógicos em análise. E, enfim, quanto a letramento, os fundamentos dos Estudos Culturais parecem-nos preteridos em favor de distinções entre letrar e alfabetizar, tendo presente que, para tais estudos, letramento não poderia constar como "estando em perspectiva". 


\section{Considerações finais}

Retomando nosso objetivo, compreendemos que ambos os programas contemplam os movimentos de que tratamos aqui, os quais são inequívocas ingrediências da alfabetização. Não é possível alfabetizar sem que o sujeito processe cognitivamente o sistema de escrita, o que implica um percurso psicogenético, o qual requer historiar-se em favor da interação social, em que os usos sociais da escrita se justificam como letramento. Assim, formar alfabetizadores implica apropriação quadripartite: sistema/psicogênese/historicidade/cultura(s).

A questão que se coloca, porém, é como lidar com esses movimentos de modo congruente. E essa congruência não nos parece haver em ambos os programas, rompendo-se não só a continuidade entre eles na formação docente, mas sua própria continuidade interna, visto que não parece possível pospor tais movimentos em sequência ou alternância. É a concepção de língua que os hierarquiza, estabelecendo o que é finalístico e o que é instrumental.

Talvez esse seja o maior desafio dos processos educativos para que de fato "continuem" a formação docente, 7 suplantando a condição de se posporem cronologicamente nesse mister. Para que haja congruência e, se houver, a continuidade da formação se dê, importa a assunção de uma concepção de língua específica, o que exigirá a adoção de uma epistemologia também específica que, por si mesma, sinalize para o que é finalístico e o que é instrumental.

Fica, pois, o desafio para as universidades, na sua complexa relação com a educação básica, porque fazer isso se contrapõe a "lotear" fascículos/cadernos a serem escritos por autores de centros acadêmicos que nem sempre se afinam sob o ponto de vista filosófico-epistemológico e, talvez mais que isso, que nem sempre conversem sobre essas dissintonias ao produzirem materiais pedagógicos para programas federais em um país "continental" como o nosso.

\section{Referências bibliográficas}

ABDALA MARTINS, L. Continuidade da formação na formação continuada: um estudo sobre programas federais no campo da alfabetização. 2017. 148 f. Dissertação (Mestrado em Linguística) - Centro de Comunicação e Expressão, Universidade Federal de Santa Catarina, Florianópolis, 2017.

BAKHTIN, M. Estética da criação verbal. São Paulo: Martins Fontes, 1997.

BAKHTIN, M. Os gêneros do discurso. In: BAKHTIN, M. Estética da criação verbal. 4. ed. São Paulo: Martins Fontes, 2003. p. 261-306.

\footnotetext{
${ }^{7}$ Este estudo teve como objetivo problematizar incongruências filosófico-epistemológicas entre programas federais incumbidos de "dar continuidade" à formação docente. Discutir as implicações do que problematizamos relativas a como, então, "lidar com a formação continuada doravante" é questão a requerer outros artigos.
} 
BAKHTIN, M. Para uma filosofia do ato responsável. São Carlos: Pedro \& João Editores, 2010.

BARTON, D. Literacy: an introduction to the ecology of written language. 2. ed. Oxford, UK: Blackwell Publishing, 2010.

BRASIL. Ministério da Educação (MEC). Secretaria de Educação Básica (SEB). Pacto nacional pela alfabetização na idade certa: formação do professor alfabetizador: caderno de apresentação. Brasília, 2012a. 40 p. Disponível em: < https://wp.ufpel. edu.br/obeducpacto/files/2019/08/Caderno-de-Apresentacao.pdf>. Acesso em: 30 set. 2020.

BRASIL. Ministério da Educação (MEC). Secretaria de Educação Básica (SEB). Pacto nacional pela alfabetização na idade certa: currículo na alfabetização: concepções e princípios - ano 01, unidade 01. Brasília, 2012b. 47 p. Disponível em: < https:// wp.ufpel.edu.br/obeducpacto/files/2019/08/Unidade-1.pdf> . Acesso em: 30 set. 2020.

BRASIL. Ministério da Educação (MEC). Secretaria de Educação Básica (SEB). Pacto nacional pela alfabetização na idade certa: planejamento escolar: alfabetização e ensino da língua portuguesa - ano 01, unidade 02. Brasília, 2012c. 48 p. Disponível em: <https://wp.ufpel.edu.br/obeducpacto/files/2019/08/Unidade-2.pdf> . Acesso em: 30 set. 2020.

BRASIL. Ministério da Educação (MEC). Secretaria de Educação Básica (SEB). Pacto nacional pela alfabetização na idade certa: a aprendizagem do sistema de escrita alfabética - ano 01, unidade 03. Brasília, 2012d. 48 p. Disponível em: < https:// wp.ufpel.edu.br/obeducpacto/files/2019/08/Unidade-3.pdf>. Acesso em: 30 set. 2020.

BRASIL. Ministério da Educação (MEC). Secretaria de Educação Básica (SEB). Pacto nacional pela alfabetização na idade certa: os diferentes textos em salas de alfabetização - ano 01, unidade 05. Brasília, 2012e. [48] p. Disponível em: $<$ https://wp.ufpel.edu.br/obeducpacto/files/2019/08/Unidade-5.pdf> . Acesso em: 30 set. 2020.

BRASIL. Ministério da Educação (MEC). Secretaria de Educação Básica (SEB). Pacto nacional pela alfabetização na idade certa: a apropriação do sistema de escrita alfabética e a consolidação do processo de alfabetização - ano 02, unidade 03. Brasília, 2012f. 48 p. Disponível em: <https://wp.ufpel.edu.br/obeducpacto/ files/2019/08/Unidade-3-1.pdf>. Acesso em: 30 set. 2020.

BRASIL. Ministério da Educação (MEC). Secretaria de Educação Básica (SEB). Pacto nacional pela alfabetização na idade certa: o trabalho com gêneros textuais na sala de aula - ano 02, unidade 05. Brasília, 2012g. [48] p. Disponível em: $<$ https://wp.ufpel.edu.br/obeducpacto/files/2019/08/Unidade-5-1.pdf>. Acesso em: 30 set. 2020.

BRASIL. Ministério da Educação (MEC). Secretaria de Educação Básica (SEB). Pacto nacional pela alfabetização na idade certa: currículo inclusivo: o direito de ser 
alfabetizado - ano 03, unidade 01, Brasília, 2012h. 48 p. Disponível em: < https:// wp.ufpel.edu.br/obeducpacto/files/2019/08/Unidade-1-2.pdf>. Acesso em: 30 set. 2020.

BRASIL. Ministério da Educação (MEC). Secretaria de Educação Básica (SEB). Pacto nacional pela alfabetização na idade certa: planejamento e organização da rotina na alfabetização - ano 03, unidade 02. Brasília, 2012i. 47 p. Disponível em: $<$ https://wp.ufpel.edu.br/obeducpacto/files/2019/08/Unidade-2-2.pdf>. Acesso em: 30 set. 2020 .

BRASIL. Ministério da Educação (MEC). Secretaria de Educação Básica (SEB). Pacto nacional pela alfabetização na idade certa: o último ano do ciclo de alfabetização: consolidando os conhecimentos - ano 03, unidade 03. Brasília, 2012j. 48 p. Disponível em: <https://wp.ufpel.edu.br/obeducpacto/files/2019/08/Unidade-3-2. pdf>. Acesso em: 30 set. 2020.

BRASIL. Ministério da Educação (MEC). Secretaria de Educação Básica (SEB). Pró-Letramento: programa de formação continuada de professores dos anos iniciais do ensino fundamental - guia geral. Brasília: MEC, 2012L. 8 p. Disponível em: <http://portal.mec.gov.br/index.php?option=com_ docman $\&$ view $=$ download\&alias $=6001$-guiageral $\&$ Itemid $=30192>$. Acesso em: 30 set. 2020.

BRASIL. Ministério da Educação (MEC). Secretaria de Educação Básica (SEB). Pró-Letramento: programa de formação continuada de professores dos anos iniciais do ensino fundamental - alfabetização e linguagem. Brasília, 2008. [364 p.]. Conteúdo: 8 fascículos com paginação independente; foram citados: 1) Capacidades linguísticas: alfabetização e letramento, 60 p.; 4) Organização e uso da biblioteca escolar e das salas de aula, 45 p.; 7) Modos de falar, modos de escrever, 39 p.; Complementar [relatos sobre ação pedagógica], 43 p. Disponível em: <http://portal.mec.gov.br/index.php?option=com_ docman\&view $=$ download\&alias $=6002$-fasciculo-port\&category_slug $=$ julho2010-pdf\&Itemid=30192> . Acesso em: 30 set. 2020.

BRITTO, L. P. L. O revés do reverso. São Paulo: Pulo do Gato, 2015.

DEHAENE, S. Os neurônios da leitura. Porto Alegre: Artmed, 2012.

DOLZ, J.; SCHNEUWLY, B. Gêneros e progressão em expressão oral e escrita: elementos para reflexões sobre uma experiência suíça (francófona). In: DOLZ, J.; SCHNEUWLY, B. Gêneros orais e escritos na escola. Campinas: Mercado de Letras, 2004. p. 95-128.

DUARTE, N. Vigotski e o aprender a aprender: crítica às apropriações neoliberais e pós-modernas da teoria vigotskiana. 3. ed. Campinas: Autores Associados, 2004.

FARACO, C. A. Pesquisa aplicada em linguagem: alguns desafios para o novo milênio. DELTA: Documentação de Estudos em Lingüística Teórica e Aplicada, São Paulo, v. 17, n. 3, p. 1-9, 2001. Edição Especial. 
FERREIRO, E.; TEBEROSKY, A. Psicogênese da língua escrita. Porto Alegre:

Artmed, 1991. [Nos excertos [xvii], [xxviii] e [xx], foi citada a edição de 1986].

GERALDI, J. W. A aula como acontecimento. São Carlos: Pedro \& João Editores, 2010 .

GOMBERT, J. E. Atividades metalinguísticas e aprendizagem da leitura. In:

MALUF, M. R. Metalinguagem e aquisição da escrita: contribuições da pesquisa para a prática da alfabetização. São Paulo: Casa do Psicólogo, 2003. p. 19-63.

HEATH, S. B. What no bedtime story means: narrative skills at home and school. In: DURANTI, A. (Org.) Linguistic anthropology: a reader. Oxford, UK: Blackwell Publishing, 2001. p. 318-331.

KALANTZIS, M.; COPE, B. Changing the role of schools. In: KALANTZIS, M.; COPE, B. (Ed.). Multiliteracies. London: Routledge, 2006. p. 121-149.

KLEIMAN, A. Modelos de letramento e práticas de alfabetização na escola. In: KLEIMAN, A. Os significados do letramento: uma nova perspectiva sobre a prática social da escrita. Campinas: Mercado de Letras, 1995. p. 15-64.

LIBERMANN, I. Y. Segmentation of the spoken word and reading aquisition. Bulletin of the Orton Society, Washington, v. 23, p. 65-77, 1973.

LYOTARD, J. F. A condição pós-moderna. 15. ed. Rio de Janeiro: José Olympio, 2013.

MORAIS, J. A arte de ler. São Paulo: Unesp, 1996.

PIAGET, J. Problemas gerais da investigação interdisciplinar e mecanismos comuns. Lisboa: Bertrand, 1973.

SAUSSURE, F. Curso de linguística geral. São Paulo: Cultrix, 2012.

SAVIANI, D.; DUARTE, N. A formação humana na perspectiva históricoontológica. Revista Brasileira de Educação, Rio de Janeiro, v. 15, n. 45, p. 422590, set./dez. 2010.

SCLIAR-CABRAL, L. Avanços das neurociências para a alfabetização e a leitura. Letras de Hoje, Porto Alegre, v. 48, p. 277-282, jul./set. 2013.

SCHNEUWLY; DOLZ, 2004 ver Dolz, J.; Schneuwly, B., 2004.

SOARES, M. Letramento: um tema em três gêneros. Belo Horizonte: Autêntica, 1998.

STREET, B. Literacy in theory and practice. Cambridge: Cambridge University Press, 1984. 
STREET, B. Literacy events and literacy practices: theory and practice in the New Literacy Studies. In: MARTIN-JONES, M.; JONES, K. (Org.). Multilingual literacies: readind and writing different worlds. Amsterdam: John Benjamins, 2000. p. 17-29.

VOLOCHÍNOV, V. N. A construção da enunciação e outros ensaios. São Carlos: Pedro \& João Editores, 2013.

VOLÓCHINOV, V. N. Marxismo e filosofia da linguagem. São Paulo: Editora 34, 2017.

VYGOTSKI, L. S. Obras escogidas. Madri: Visor, 1982. t. II.

VYGOTSKY, L. S. A formação social da mente: o desenvolvimento dos processos psicológicos superiores. 3. ed. São Paulo: Martins Fontes, 1989a.

YIN, R. K. Estudo de caso: planejamento e métodos. 3. ed. Porto Alegre: Bookman, 2005.

Laiana Abdala Martins, mestre em Linguística pela Universidade Federal de Santa Catarina (UFSC), integra o Grupo de Pesquisa Cultura Escrita e Escolarização, no âmbito do Núcleo de Estudos em Linguística Aplicada (Nela/UFSC).

laiana_abdala@hotmail.com

Mary Elizabeth Cerutti-Rizzatti, doutora em Letras pela Universidade Federal do Rio Grande do Sul (UFRGS), com pós-doutorado em Filosofia da Linguagem na Università degli Studi Aldo Moro, em Bari, Itália, é professora da Universidade Federal de Santa Catarina (UFSC). Nessa universidade, foi vice-coordenadora do Programa de Pós-Graduação em Linguística, em 2009 e 2010, e coordenou o Programa PróLetramento Linguagem, de 2010 a 2012. É líder do Grupo de Pesquisa Cultura Escrita e Escolarização, no âmbito do Núcleo de Estudos em Linguística Aplicada (Nela/UFSC).

ma.rizzatti@gmail.com

Recebido em 26 de março de 2020

Aprovado em 20 de julho de 2020 